Pacific Journal of Mathematics

A TOPOLOGICAL CHARACTERIZATION OF BANACH DO 


\title{
A TOPOLOGICAL CHARACTERIZATION OF BANACH CONTRACTIONS
}

\author{
SOLOMON LEADER
}

A continuous operator $T$ on a metric space $(X, \rho)$ is a Banach contraction with fixed point $p$ under some metric $\sigma$ topologically equivalent to $\rho$ if, and only if, every orbit $T^{n} x$ converges to $p$ and the convergence is uniform on some neighborhood of $p$. For $\sigma$ to be bounded we demand that the convergence be uniform on $X$. The latter condition with $T$ uniformly continuous characterizes the case for $\sigma$ bounded and uniformly equivalent to $\rho$.

A Banach contraction is an operator $T$ on a metric space $(X, \sigma)$ such that for some $a<1$

$$
\sigma(T x, T y) \leqq \alpha \sigma(x, y) \quad \text { for all } x, y \text { in } X .
$$

( $T$ is called nonexpansive if (1) holds with $\alpha=1$.) By induction (1) extends to

$$
\sigma\left(T^{n} x, T^{n} y\right) \leqq a^{n} \sigma(x, y)
$$

for all $n$ in the set $N$ of all natural numbers. By the Banach Contraction Theorem a Banach contraction $T$ on a complete metric space has a unique fixed point $p=T p$. From (2) with $y=p$

$$
\sigma\left(T^{n} x, p\right) \leqq a^{n} \sigma(x, p) .
$$

Since $a^{n}$ converges to 0 (3) implies

$$
T^{n} x \longrightarrow p \quad \text { for all } x \text { in } X .
$$

Moreover, taking any ball about $p$, we conclude from (3) that

$$
T^{n} B \longrightarrow p \quad \text { for some neighborhood } B \text { of } p \text {. }
$$

That is, (4) holds uniformly for $x$ in $B$. We contend that a continuous $T$ satisfying (4) and (5) is topologically equivalent to a Banach contraction. We shall also get topological and uniform characterizations of Banach contractions on bounded spaces. Our proofs depend on two lemmas which extend constructions used by Ludvik Janos [1] to characterize Banach contractions on compact spaces.

For any metric $\rho$ we use the notation $\rho[$ to denote the $\rho$ diameter of sets.

THEOREM. Let $T$ operate on a metric space $(X, \rho)$. 
(i) There exists a metric $\sigma$ topologically equivalent to $\rho$ on $X$ such that $T$ is a Banach contraction under $\sigma$ with fixed point $p$ if, and only if, $T$ is continuous and both (4) and (5) hold.

(ii) There exists a bounded metric $\sigma$ topologically equivalent to $\rho$ on $X$ such that $T$ is a Banach contraction under $\sigma$ with fixed point $p$ if, and only if, $T$ is continuous and $T^{n} X \rightarrow p$.

(iii) There exists a bounded metric $\sigma$ uniformly equivalent to $\rho$ on $X$ such that $T$ is a Banach contraction under $\sigma$ if, and only if, $T$ is uniformly continuous and

$$
\rho\left[T^{n} X\right] \longrightarrow 0 \text {. }
$$

Lemma 1. For $T$ an operator on $(X, \rho)$ conditions (a) and (b) are equivalent in their corresponding versions:

(a) $T$ and its iterates are equicontinuous (equiuniformly continuous).

(b) $T$ is nonexpansive under some metric $\bar{\rho}$ topologically (uniformly) equivalent to $\rho$. $\bar{\rho}$ may be assumed bounded.

Proof. That (b) implies (a) is trivial. To prove the converse we may assume $\rho \leqq 1$ since we can replace $\rho$ by the uniformly equivalent metric $\operatorname{Min}\{\rho, 1\}$. Then define

$$
\bar{\rho}(x, y)=\sup _{n \geq 0} \rho\left(T^{n} x, T^{n} y\right) .
$$

$\bar{\rho}$ is readily seen to be a metric with $\rho \leqq \bar{\rho} \leqq 1$. So $\rho$ is uniformly continuous with respect to $\bar{\rho}$. By (a) and (7) $\bar{\rho}$ is (uniformly) continuous with respect to $\rho$. Finally, (7) implies $T$ is nonexpansive under $\bar{\rho}$.

LEMMa 2. Let $\left\langle B_{n}\right\rangle$ be a sequence of subsets of $(X, \rho)$ indexed by the set $Z$ of all integers (positive, negative, and zero) so that the conditions (8), (9), and (10) hold:

$$
\begin{gathered}
B_{n+1} \subseteq B_{n} \quad \text { for all } n \text { in } Z, \\
U_{n \in Z} B_{n}^{\circ}=X,
\end{gathered}
$$

where the superscript denotes interior, and

$$
\rho\left[B_{n}\right] \longrightarrow 0 \text { as } n \longrightarrow \infty \text {. }
$$

Given $0<a<1$ let $\sigma$ be the largest pseudometric on $X$ such that

$$
\sigma \leqq a^{n} \rho \quad \text { on } B_{n} \text { for all } n \text { in } Z \text {. }
$$

Then 


$$
\rho \leqq a^{-n} \sigma+\rho\left[B_{n}\right] \quad \text { for all } n \text { in } Z \text {. }
$$

So $\rho$ is uniformly continuous with respect to $\sigma$. Hence $\sigma$ is a metric. Moreover, $\sigma$ is topologically equivalent to $\rho$. If $B_{0}=X$ then $\sigma$ is uniformly equivalent to $\rho$. Finally, if $T$ is a nonexpansive operator on $(X, \rho)$ such that

$$
T B_{n} \cong B_{n+1} \quad \text { for all } n \text { in } Z
$$

then (1) holds.

Proof. Let $S(x, y)$ be the set of all finite sequences

$$
\left\{\begin{array}{l}
\left\langle x_{i}, n_{i}\right\rangle_{i=0,1}, \cdots, m \text { in } X \times Z \text { such that } x_{0}=x, \\
x_{m}=y, \text { and both } x_{i-1} \text { and } x_{i} \text { belong to } B_{n_{i}} \text { for } \\
i=1, \cdots, m .
\end{array}\right.
$$

Then the largest pseudometric $\sigma$ satisfying (11) is

$$
\sigma(x, y)=\inf _{S(x, y)} \sum_{i=1}^{m} a^{n_{i}} \rho\left(x_{i-1}, x_{i}\right)
$$

as the reader can routinely verify. Given $n$ in $Z$ we contend that for any member (14) of $S(x, y)$

$$
\alpha^{n} \rho(x, y) \leqq \sum_{i=1}^{m} \alpha^{n_{i}} \rho\left(x_{i-1}, x_{i}\right)+a^{n} \rho\left[B_{n}\right] .
$$

Case 1. No $x_{i} \in B_{n}$. Then $n_{i}<n$ by (8) and the last condition in (14). Therefore

$$
a^{n}<a^{n_{i}}
$$

for $i=1, \cdots, m$. By the triangle inequality and (17),

$$
\alpha^{n} \rho(x, y) \leqq a^{n} \sum_{i=1}^{m} \rho\left(x_{i-1}, x_{i}\right) \leqq \sum_{i=1}^{m} a^{n_{i}} \rho\left(x_{i-1}, x_{i}\right)
$$

which gives (16) in Case 1.

Case 2. Some $x_{i} \in B_{n}$. Let $x_{j}$ be the first and $x_{k}$ the last such $x_{i}$. Let $J=[1, j] \cup[k+1, m]$ in $N$. Then $\rho(x, y) \leqq \sum_{i \in J} \rho\left(x_{i-1}, x_{i}\right)+$ $\rho\left(x_{j}, x_{k}\right) \leqq \sum_{i \in j} \rho\left(x_{i-1}, x_{i}\right)+\rho\left[B_{n}\right]$. Multiplying by $a^{n}$ and noting that (17) holds for all $i$ in $J$, we get $a^{n} \rho(x, y) \leqq \sum_{i \in J} a^{n_{i}} \rho\left(x_{i-1}, x_{i}\right)+a^{n} \rho\left[B_{n}\right]$ which implies (16) in Case 2.

Now (15) and (16) imply $a^{n} \rho \leqq \sigma+a^{n} \rho\left[B_{n}\right]$ which gives (12).

Given $\varepsilon>0$ use (10) to get $n$ such that $\rho\left[B_{n}\right]<\varepsilon / 2$. Take $\delta=a^{n}(\varepsilon / 2)$. Then by (12), $\sigma<\delta$ implies $\rho<\varepsilon$. So $\rho$ is uniformly continuous with respect to $\sigma$, which implies $\sigma$ is a metric. (9) implies 
$\sigma$ is continuous with respect to $\rho$ since continuity holds on each $B_{n}$ by (11). If $B_{0}=X$ then $\sigma \leqq \rho$ by (11) at $n=0$, so $\sigma$ is uniformly continuous with respect to $\rho$.

Finally, if $T$ is nonexpansive and satisfies (13) consider any member (14) of $S(x, y)$. Then $\left\langle T x_{i}, n_{i}+1\right\rangle$ belongs to $S(T x, T y)$ by (13). Therefore, since $T$ is nonexpansive under $\rho$, (15) yields $\sigma(T x, T y) \leqq \sum_{i=1}^{m} a^{n_{i}+1} \rho\left(T x_{i-1}, T x_{i}\right) \leqq a \sum_{i=1}^{m} a^{n_{i}} \rho\left(x_{i-1}, x_{i}\right)$ which gives (1) by (15).

We can now prove the theorem. The direct implications in (i), (ii), and (iii) follow from the Banach Contraction Theorem and the topological (uniform) invariance of the conclusions. So we need only prove the converses.

To prove (i) let $T$ be continuous and satisfy (4) and (5). We contend first that the $T^{n}$ are equicontinuous for all $n$ in $N$. That is, given $q$ in $X$ and $\varepsilon>0$ there exists a neighborhood $D$ of $q$ such that

$$
\rho\left[T^{n} D\right]<\varepsilon
$$

for all $n$ in $N$. To get such a $D$ choose $m$ in $N$ large enough to ensure that for $B$ some neighborhood of $p$ satisfying (5)

$$
T^{m} q \in B^{0}
$$

by (4) and

$$
\rho\left[T^{k} B\right]<\varepsilon \quad \text { for all } k>m
$$

by (5). Since $T$, and hence each interate of $T$, is continuous there exists a neighborhood $D$ of $q$ such that (18) holds for all $n \leqq 2 m$. By (19) $T^{-m} B$ is a neighborhood of $q$ since $T^{m}$ is continuous. So we may assume $D \subseteq T^{-m} B$. For $n>2 m$ take $k=n-m$ to get $k>m$ and $T^{n} D \subseteq T^{k} B$. So (20) implies (18) for $n>2 m$. Thus (18) holds for all $n$ in $N$.

Hence we may assume by Lemma 1 that $T$ is nonexpansive under $\rho$. Consequently each open ball about $p$ is mapped into itself by $T$ since $p=T p$ by (4) and the continuity of $T$. Hence in (5) we may assume $B$ is open and

$$
T B \subseteq B
$$

Apply Lemma 2 with

$$
B_{n}=T^{n} B \quad \text { for all } n \text { in } Z \text {. }
$$

Indeed, (21) and (22) imply (8) and (13). (10) follows from (22) and (5). Since $B$ is open and $T$ is continuous, $B_{n}$ is open for $n<0$ by 
(22). So (9) follows from (4) and (22). Hence Lemma 2 applies and gives (i).

To prove (ii) let $T$ be continuous and $T^{n} X \rightarrow p$. These conditions are just those in (i) with $B=X$. So we get $\sigma$ from Lemmas 1 and 2 exactly as in the proof of (i). But now $\sigma \leqq \rho$ from (11) at $n=0$ since $B_{0}=X$ under (22). Thus, since we may assume $\rho$ is bounded, $\sigma$ is bounded.

To prove (iii) let $T$ be uniformly continuous and satisfy (6). We contend first that the $T^{n}$ are equiuniformly continuous for all $n$ in $N$. Given $\varepsilon>0$ choose $m$ by (6) so that

$$
\rho\left[T^{m} X\right]<\varepsilon .
$$

Since $T$, and hence each of its iterates, is uniformly continuous we can choose $\delta>0$ such that every subset $D$ of $X$ with $\rho[D]<\delta$ must satisfy

$$
\rho\left[T^{n} D\right]<\varepsilon
$$

for $n=1, \cdots, m$. But (24) holds for $n>m$ by (23). So (24) holds for all $n$ in $N$. Therefore, by the uniform version of Lemma 1 we may assume $T$ is nonexpansive under a bounded $\rho$.

Let $B_{n}=T^{n} X$. Then (8), (9), and (13) are trivial while (10) is just (6). So Lemma 2 applies and gives (iii), which completes the proof of the theorem.

Note that (iii) is the uniform analogue of (ii). However, we have no uniform analogue of (i).

For $X$ a compact metric space each of our results (i), (ii), and (iii) reduces to the theorem of Ludvik Janos [1]: An operator $T$ on a compact metric space $(X, \rho)$ is a Banach contraction under some metric $\sigma$ topologically equivalent to $\rho$ if, and only if, $T$ is continuous and the $T^{n} X$ intersect at only one point.

To get this theorem from (i), (ii), or (iii) one can use the following remarks about a continuous $T$ operating on a compact $(X, \rho)$ :

(a) Continuity of $T$ is equivalent to uniform continuity,

(b) Every continuous metric $\sigma$ on $X$ is bounded,

(c) $\sigma$ is topologically equivalent to $\rho$ if, and only if, $\sigma$ is uniformly equivalent to $\rho$,

(d) The intersection $I$ of the compact nested after-images $T^{n} X$ is nonempty and $\rho\left[T^{n} X\right] \rightarrow \rho[I]$. (See Lemma $\mathrm{A}$ in [2].)

\section{REFERENCES}

1. Ludvik Janos, A converse of Banach's contraction theorem, Proc. Amer. Math. Soc., 18 (1967), 287-289. 
2. S. Leader and S. L. Hoyle, Contractive fixed points, Fund. Math., 87 (1975), 93-108. Received December 3, 1974.

RUTGERS UNIVERSITY

NEW BRUNSWICK, NJ 08903 


\section{PACIFIC JOURNAL OF MATHEMATICS}

\section{EDITORS}

RICHARD ARENS (Managing Editor)

University of California

Los Angeles, CA 90024

R. A. BEAUMONT

University of Washington

Seattle, WA 98105

C. C. Moore

University of California

Berkeley, CA 94720

\section{J. DugundJI}

Department of Mathematics

University of Southern California

Los Angeles, CA 90007

R. Finn and J. Milgram

Stanford University

Stanford, CA 94305

\section{ASSOCIATE EDITORS}

\section{E. F. BECKENBACH}

B. H. NEUMANN

F. WoLF

K. YOSHIDA

\section{SUPPORTING INSTITUTIONS}

\author{
UNIVERSITY OF BRITISH COLUMBIA \\ CALIFORNIA INSTITUTE OF TECHNOLOGY \\ UNIVERSITY OF CALIFORNIA \\ MONTANA STATE UNIVERSITY \\ UNIVERSITY OF NEVADA \\ NEW MEXICO STATE UNIVERSITY \\ OREGON STATE UNIVERSITY \\ UNIVERSITY OF OREGON \\ OSAKA UNIVERSITY
}

\author{
UNIVERSITY OF SOUTHERN CALIFORNIA \\ STANFORD UNIVERSITY \\ UNIVERSITY OF HAWAII \\ UNIVERSITY OF TOKYO \\ UNIVERSITY OF UTAH \\ WASHINGTON STATE UNIVERSITY \\ UNIVERSITY OF WASHINGTON \\ AMERICAN MATHEMATICAL SOCIETY
}

The Supporting Institutions listed above contribute to the cost of publication of this Journal, but they are not owners or publishers and have no responsibility for its content or policies.

Mathematical papers intended for publication in the Pacific Jaurnal of Mathematics should be in typed form or offset-reproduced, (not dittoed), double spaced with large margins. Please do not use built up fractions in the text of your manuscript. You may however, use them in the displayed equations. Underline Greek letters in red, German in green, and script in blue. The first paragraph or two must be capable of being used separately as a synopsis of the entire paper. Items of the bibliography should not be cited there unless absolutely necessary, in which case they must be identified by author and Journal, rather than by item number. Manuscripts, in triplicate, may be sent to any one of the editors. Please classify according to the scheme of Math. Reviews, Index to Vol. 39. All other communications should be addressed to the managing editor, or Elaine Barth, University of California, Los Angeles, California, 90024.

The Pacific Journal of Mathematics expects the author's institution to pay page charges, and reserves the right to delay publication for nonpayment of charges in case of financial emergency

100 reprints are provided free for each article, only if page charges have been substantially paid. Additional copies may be obtained at cost in multiples of 50 .

The Pacific Journal of Mathematics is issued monthly as of January 1966. Regular subscription rate: $\$ 7200$ a year (6 Vols., 12 issues). Special rate: $\$ 36.00$ a year to individual members of supporting institutions.

Subscriptions, orders for back numbers, and changes of address should be sent to Pacific Journal of Mathematics, 103 Highland Boulevard, Berkeley, California, 94708.

PUBLISHED BY PACIFIC JOURNAL OF MATHEMATICS, A NON-PROFIT CORPORATION

Printed at Kokusai Bunken Insatsusha (International Academic Printing Co., Ltd.). 8-8, 3-chome, Takadanobaba, Shinjuku-ku, Tokyo 160, Japan.

Copyrit (C) 1975 by Pacific Journal of Mathematics Manufactured and first issued in Japan 


\section{Pacific Journal of Mathematics \\ Vol. 69, No. $2 \quad$ June, 1977}

Carol Alf and Thomas Alfonso O'Connor, Unimodality of the Lévy spectral

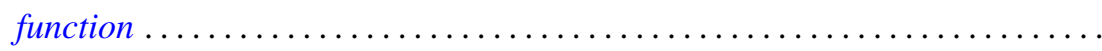

S. J. Bernau and Howard E. Lacey, Bicontractive projections and reordering of

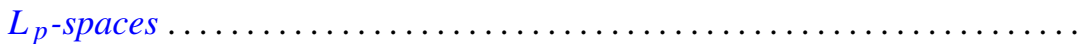

Andrew J. Berner, Products of compact spaces with bi-k and related spaces..... 303

Stephen Richard Bernfeld, The extendability and uniqueness of solutions of ordinary differential equations ...............................

Marilyn Breen, Decompositions for nonclosed planar m-convex sets ..........

Robert F. Brown, Cohomology of homomorphisms of Lie algebras and Lie

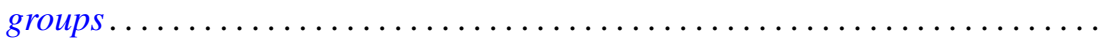

Jack Douglas Bryant and Thomas Francis McCabe, A note on Edelstein's iterative test and spaces of continuous functions ....................

Victor P. Camillo, Modules whose quotients have finite Goldie dimension ....... 333

David Downing and William A. Kirk, A generalization of Caristi's theorem with

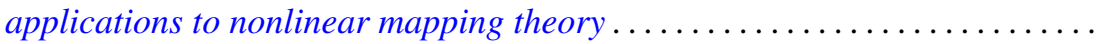

Daniel Reuven Farkas and Robert L. Snider, Noetherian fixed rings ...........

Alessandro Figà-Talamanca, Positive definite functions which vanish at

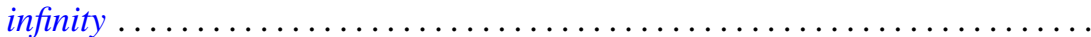

Josip Globevnik, The range of analytic extensions .................. 365

André Goldman, Mesures cylindriques, mesures vectorielles et questions de

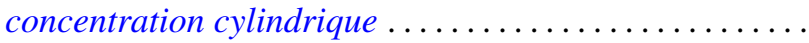

Richard Grassl, Multisectioned partitions of integers..........

Haruo Kitahara and Shinsuke Yorozu, A formula for the normal part of the

Laplace-Beltrami operator on the foliated manifold .... .

Marvin J. Kohn, Summability $R_{r}$ for double series .........

Charles Philip Lanski, Lie ideals and derivations in rings with involution ..

Solomon Leader, A topological characterization of Banach contractions . .

Daniel Francis Xavier O’Reilly, Cobordism classes of fiber bundles . .

James William Pendergrass, The Schur subgroup of the Brauer group . .

Howard Lewis Penn, Inner-outer factorization of functions whose Fourier series

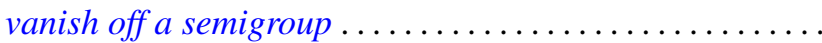

501

William T. Reid, Some results on the Floquet theory for disconjugate definite

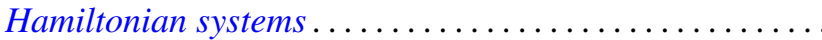

Caroll Vernon Riecke, Complementation in the lattice of convergence

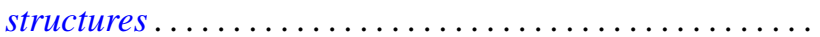

Louis Halle Rowen, Classes of rings torsion-free over their centers ......... 527

Manda Butchi Suryanarayana, A Sobolev space and a Darboux problem ....... 535

Charles Thomas Tucker, II, Riesz homomorphisms and positive linear maps.... 551

William W. Williams, Semigroups with identity on Peano continua ........... 557

Yukinobu Yajima, On spaces which have a closure-preserving cover by finite 